\title{
Preclinical models to investigate retinal ischemia: advances and drawbacks
}

\section{Gillipsie Minhas ${ }^{1}$, Ryuichi Morishita ${ }^{2}$ and Akshay Anand ${ }^{1}$ *}

${ }^{1}$ Neuroscience Research Lab, Department of Neurology, Postgraduate Institute of Medical Education and Research, Chandigarh, India

${ }^{2}$ Division of Clinical Gene Therapy, Graduate School of Medicine, Osaka University Medical School, Osaka, Japan

\section{Edited by:}

Kenneth Shindler, University of

Pennsylvania, USA

Reviewed by:

Yaping Joyce Liao, Stanford University School of Medicine, USA

Reas Khan Sulaimankutty, University

of Pennsylvania, USA

*Correspondence:

Akshay Anand, Neuroscience

Research Lab, Department of

Neurology, Postgraduate Institute of

Medical Education and Research,

Chandigarh-160012, India.

e-mail: akshay1anand@rediffmail.com
Retinal ischemia is a major cause of blindness worldwide. It is associated with various disorders such as diabetic retinopathy, glaucoma, optic neuropathies, stroke, and other retinopathies. Retinal ischemia is a clinical condition that occurs due to lack of appropriate supply of blood to the retina. As the retina has a higher metabolic demand, any hindrance in the blood supply to it can lead to decreased supply of oxygen, thus causing retinal ischemia. The pathology of retinal ischemia is still not clearly known. To get a better insight into the pathophysiology of retinal ischemia, the role of animal models is indispensable. The standard treatment care for retinal ischemia has limited potential. Transplantation of stem cells provide neuroprotection and to replenish damaged cells is an emerging therapeutic approach to treat retinal ischemia. In this review we provide an overview of major animal models of retinal ischemia along with the current and preclinical treatments in use.

Keywords: animal model, retinal ischemia, stem cells, therapeutics

\section{INTRODUCTION}

The term "ischemia" implies reduction in the blood supply to a tissue resulting in insufficiency to meet the metabolic requirements. Thus, retinal ischemia is the clinical condition when the blood supply to the retina is obstructed. The retina is an extension of central nervous system (CNS) and thus shares many embryological, functional, and anatomical characteristics with brain. The response to ischemia in retinal neurons is similar to those in other parts of CNS. Nevertheless, retina is more resistant to ischemic injury than the brain (Tso and Jampol, 1982).

As far as the blood supply to the retina is concerned, the mammalian retina has a dual circulation system. The major portion of blood supply goes to the choroid, i.e., $65-85 \%$ of the total supply, whereas the remaining goes to the retina through central retinal artery, which originates from ophthalmic artery (Henkind et al., 1979). Figure 1 depicts the blood supply to the eye. The extent of retinal ischemia and the region of retina affected depends on the blood supply that is obstructed (Saint-Geniez and D'Amore, 2004). The retina has a high metabolic demand. Any hindrance in the blood supply affects the exchange of substrates and products, leading to many morphological and functional changes in retina. The pathophysiology of retinal ischemia is not completely known but involves imbalance in ion transport, changes in neurotransmitter levels, oxidative stress, and finally cell death. Thus, there is a need to study the pathophysiology involved so that better therapeutic agents can be tested. As retina can be studied noninvasively the investigations into retinal ischemia may lead to a better understanding of cerebral ischemia.

\section{NEED FOR ANIMAL MODELS}

Although humans and animals have varying phenotype, they share strikingly common physiological and anatomical details. Therefore, to understand the human physiology and to test new treatments through preclinical investigations, animal experimentation has always been a core of basic and clinical research. The importance of developing animal models for retinal ischemia originates from the limitations found in the use of in vitro models. Retinal ischemia at molecular and biochemical levels can be studied in depth using an in vitro model of ischemia but the pathophysiological details can only be understood using an appropriate animal model. An ideal animal model for retinal ischemia should have parallelism with humans at anatomical, vascular, and retinal levels besides offering ease in handling and manipulation.

\section{ANIMAL MODELS OF RETINA ISCHEMIA ELEVATION OF INTRAOCULAR PRESSURE}

The model often used to cause retinal ischemia is by increasing intraocular pressure (IOP). This model involves elevation of the IOP above the systemic arterial pressure for a fixed duration of time (Peachey et al., 1993). High IOP results in global ischemia as it hampers the blood supply from both uveal and retinal circulation. In rodents, different groups have shown that IOP-induced retinal ischemia mimics the features observed in human central retinal artery occlusion (CRAO) and primary open angle glaucoma (Smith and Baird, 1952; Buchi et al., 1991).

The animal model of retinal ischemia model was first described by Smith and Baird (1952) and was further validated by Flower and Patz (1971) in cats. In rodents, the elevated IOP-induced retinal ischemia injury was induced in rats by Buchi et al. (1991). In all these studies, the IOP was increased through cannulation of the anterior chamber with a 26-gauge needle connected to an elevated chamber containing normal saline. The IOP was raised to $110 \mathrm{~mm} \mathrm{Hg}$. This method has been used in a wide range of experiments to study the alteration in protein expression, ion channel imbalance, excitotoxicity in various animal models (Hirrlinger et al., 2010; Joachim et al., 2011). Ji et al. (2005) used this model 


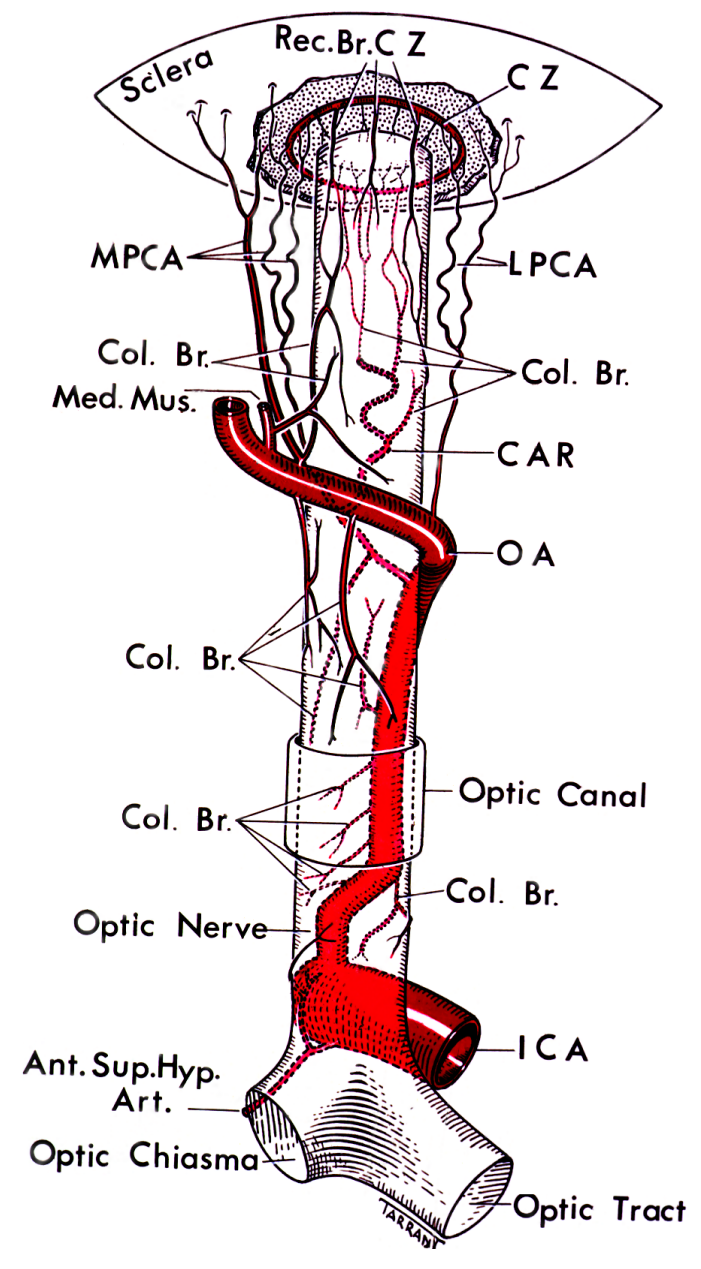

FIGURE 1 |The figure depicting the circle of Zinn-Haller and the blood supply to eye (Hayreh, 1963).

in mice to investigate the mechanism behind the retinal ganglion cell death due to retinal ischemia.

The advantages of using this model are that it is temporary and reversible, easy to create, and reproduce and there is minimal requirement of surgery or special equipments. But there is a limitation to this model that the elevated IOP can itself cause damage and hence, lead to incorrect interpretation of the data (Peachey et al., 1993).

\section{MIDDLE CEREBRAL ARTERY OCCLUSION}

It has been reported that the cerebral stroke incidents are invariably accompanied with temporary (amaurosis fugax) or permanent vision loss. A purely vascular model of retinal ischemia is the middle cerebral artery occlusion (MCAO). As the ophthalmic artery which is the source of blood supply to the inner retina originates proximal to the origin of middle cerebral artery (MCA), any hindrance in the blood flow in MCA obstructs the flow to the ipsilateral retina. This method involves occlusion of blood supply by the use of a filament inserted through external carotid artery (ECA) and internal carotid artery (ICA) and advanced into the MCA.

This procedure was first time demonstrated by Block et al. (1997) in rats that led to MCAO induced retinal ischemia. Later the same model was used to depict damage to retina through MCAO in mice (Steele et al., 2008). This model is a non-invasive and does not disrupt the blood-retina barrier or cause any mechanical damage to the retina (Kaja et al., 2003). The MCAO model has other advantages including reproducibility making it permissive for reperfusion related investigations.

\section{CHRONIC CAROTID OCCLUSION}

Retinal ischemia can also be caused by carotid artery disease in humans. This model was first induced by Block et al. (1992) in rats in order to show that the bilateral common carotid artery occlusion in rats causes functional damage to the retina. The electroretinogram studies have also shown a decrease in amplitude of b-wave 7 days after the bilateral carotid artery occlusion or twovessel occlusion (2VO). The b-wave represents the bipolar and Muller cell activity (Barnett and Osborne, 1995). Not only functional, 2VO model also causes structural damage to the retina. In another study in rats, Lavinsky et al. (2006) showed that in the animals that showed functional damage, the retinal thickness was found to be decreased and the layers that are most affected included inner and outer plexiform layers.

The 2VO model for retinal ischemia leads to permanent occlusion without any reperfusion. Due to collateral blood circulation partial blood supply to retina is retained through Circle of Willis leading to variable retinal damage.

\section{PHOTOTHROMBOSIS OF RETINAL VESSELS}

The photothrombosis or photocoagulation induced retinal ischemia model is a simple and non-invasive method. It is comparatively a new method to perform vessel occlusion. This method was first described in adult rat retina by Mosinger and Olney (1989), where the authors injected Rose Bengal, a photosensitive dye intravenously and then exposed the retina to light of a fixed wavelength $(550 \mathrm{~nm})$ leading to photothrombosis. Miller et al. (1994) used this same method in a non-human primate model, cynomolgus monkey (Macaca fascicularis), where a laser at $577 \mathrm{~nm}$ was used for causing occlusion. Buchi et al. (1994) used this model to study morphological and histological changes in retina. SchimdtKastner also used Photothrombosis to induce ischemia in rat retina and showed the ganglion cell death (Schmidt-Kastner and Eysel, 1994). Another photosensitive dye, apart from Rose Bengal, that can be used in this model, is chloro-aluminum sulfonated phthalocyanine (Kliman et al., 1994).

Like any other method, this too has its own advantages and disadvantages. Photothrombosis leads to variability in retinal damage and hence irregular damage due to variation in light exposure. It leads to permanent ischemia and can therefore not be used to study damage due to reperfusion. This method results in damage due to free-radicals.

\section{OCCLUSION OF CENTRAL RETINAL ARTERY}

The central retinal artery is the first intraorbital branch of ophthalmic artery. The CRAO causes complete inner retinal ischemia. 
In humans, the clinical features were first described by von Graefe (1859). The CRAO model has been used to induce retinal ischemia in different species. Hayreh induced transient CRAO in rhesus monkeys by clamping the central retinal artery for different time durations. This study also showed that the damage induced depends on the tolerance time for the particular species (Hayreh et al., 1980). Zhang et al. (2005) created this model in rats by intravenous injection of Rose Bengal and treating the animals with green laser. This model is used to study the pathways involved in transient retinal ischemia by mimicking the clinical features of CRAO in humans. In another study in CRAO model in rhesus monkeys, amino acid profiling was done to evaluate the role of glutamate excitotoxicity in ischemia (Kwon et al., 2005). The mouse model showing similar changes as human CRAO has been generated, where central retinal artery was occluded by laser photoactivation of Rose Bengal. The occlusion of 6-24 h showed molecular and histological changes (Goldenberg-Cohen et al., 2008). CRAO can also be achieved by another method which leads to ischemia reperfusion model. In this model a suture is placed behind the eye globe and then obstructing the blood flow by pressing the tube through which both ends of suture are passed (Prasad et al., 2010).

\section{ENDOTHELIN ADMINISTRATION}

Endothelin-1 or ET-1 is a 21 amino acid long peptide with vasoconstrictor activity. It was first purified and characterized in 1988 from the conditioned medium of cultures of porcine aortic endothelial cells (Yanagisawa et al., 1988). In humans, cardiovascular disease, renal, and ocular disorders have been associated with endothelin-1. The vasoconstrictor activity of endothelin has been demonstrated in retinal arteries in rats. In a study by Bursell et al. (1995) an approximate 17\% reduction in diameter after $10^{-7} \mathrm{M}$ concentration of ET-1 was shown. Sakaue et al. also studied the effect of endothelin on the retinal vessels after intravitreal administration of ET-1 in rabbit eyes. The authors showed a dose-dependent response, where the concentration of $10^{-6} \mathrm{M}$ caused vasoconstriction and lower concentrations caused vasodilation first with vasoconstrictions later, leading to hypoxia and retinal ischemia (Sakaue et al., 1992; Sato et al., 1993; Takei et al., 1993). In another study, ET-1 administration was used to obstruct the central retinal artery causing ganglion cell loss in retina (Masuzawa et al., 2006).

No problems such as inflammation or infection are associated with this model, but this has a limitation of ET-1 dose. Also it may show some undesirable effect due to systemic circulation to other tissues.

\section{CURRENT AND POTENTIAL THERAPEUTIC STRATEGIES FOR RETINAL ISCHEMIA}

Current treatments for retinal ischemia involve recovery of the blood circulation in retina that will prevent further damage and permanent vision loss. Combination of strategies are being used to treat retinal ischemia including intravitreal or retinal vein administration of anticoagulants such as tissue-plasminogen activator (t-PA), hemodilution, pan-retinal laser photocoagulation, or antiVEGF antibodies (Lucentis or Avastin). Ischemic conditions in retina have been shown to up-regulate the expression of vascular endothelial growth factor or VEGF, a potent angiogenic factor. This change in VEGF levels leads to retinal neovascularization or growth of abnormal blood vessels. Neutralizing VEGF through monoclonal antibodies has been shown to block neovascularization. This technique was tested in a primate model of retinal ischemia induced by laser. The study showed that VEGF was inhibited in vivo when proteins containing human (Flt) or mouse (Flk) VEGF receptors attached to IgG were administered (Aiello et al., 1995). This showed almost complete inhibition of neovascularization. Laser photocoagulation or pan-retinal laser treatment is used to decrease the neovascularization or growth of abnormal blood vessels, thus decreasing the damage to the retina.

All these strategies that are being used have their own limitations. The anticoagulants and vasodilators are effective only in limited cases of retinal ischemia, such as CRAO patients, while the laser treatment is effective only when given early (Rumelt et al., 1999). This unavailability of effective treatment options has led to development of various other neuroprotective agents. Other possible therapeutic agents include NMDA receptor blockers or inhibitors, catalase and thioredoxin (free-radical scavengers), calcium channel blockers, and many others. These novel drugs and chemical compounds have been tested in different animal models of retinal ischemia, showing positive outcome and potential as future therapeutics. Various antagonists and blockers have been demonstrated to reduce the damage caused through ischemia. NMDA receptor antagonists have shown neuroprotective effect in retinal ischemia animal models. Different NMDA receptor blockers that have been tested in preclinical studies are dextromethorphan, MK-801, memantine (Cao et al., 1994; Lam et al., 1997; Osborne et al., 1999). Blockers of calcium channels have also been tested in animal models and have shown to decrease neurotoxicity (Melena et al., 1999). Retinal ischemia damage is exacerbated by free-radicals. Free-radicals are generated by reoxidation of compounds during reperfusion and leads to oxidative stress (Gilgun-Sherki et al., 2002). Thus, different free-radical scavengers can be used for treatment. Rios et al. compared the freeradical scavengers - SOD or superoxide dismutase and DMTU or dimethylthiourea. In an IOP-induced retinal ischemia model in rats, intravitreal administration of both the compounds has shown to potential in recovery. In this model, DMTU led to $40 \%$ functional recovery while SOD treatment showed a $99 \%$ recovery when assessed through electroretinogram (Rios et al., 1999).

Apart from these, growth factors such as CNTF, bFGF, NGF, BDNF, PEDF, HGF have been tested in retinal ischemiareperfusion models for therapeutic potential (Unoki and LaVail, 1994; Ogata et al., 2001; Shibuki et al., 2002). These therapeutic agents have short half-life and thus require repeated administration resulting in side-effects. This limitation can be overcome by the delivery of the gene of neurotrophic factors directly using gene therapy. Viral vectors have been used successfully to transfect cells in eye (Bennett et al., 1994; Flannery et al., 1997; Di Polo et al., 1998). Wu et al. used recombinant Adeno-associated virus (AAV) vector to transfer GDNF intravitreally in rats subjected to elevated IOP. GDNF is a known neurotrophic factor 
that reduces ischemic injury (Wu et al., 2004). It has also been shown in different studies that GDNF protects photoreceptors and inhibits apoptosis. Another group of neuroprotectants that have shown positive results in animal models by inhibiting apoptosis are the inhibitors of apoptosis (IAP) which inhibit caspases. Most tested IAP is the XIAP which blocks caspases 3, 7, and 9 (Deveraux et al., 1997; Xu et al., 1999; Eberhardt et al., 2000; Holcik et al., 2001; McKinnon et al., 2002; Petrin et al., 2003). Renwick et al. reported that XIAP overexpression protects the retina from transient ischemia induced by elevation of IOP in rats. In this study the authors intravitreally administered AAV vector expressing XIAP and demonstrated structural and functional protection in retinal ischemia model (Renwick et al., 2006). But it has a limitation of being ineffective in the cases where retinal ischemia occurs suddenly.

\section{ROLE OF STEM CELL THERAPY IN RETINAL ISCHEMIA}

The treatment strategies discussed in the previous section have limited potential. Stem cells are an emerging branch used in the treatment of a wide variety of disorders (Lenka and Anand, 2009). The use of stem cells from different sources are being studied and clinical trials are being carried out for disorders such as diabetes, spinal cord injury, fractures, cardiovascular, and neurological disorders. Replenishment of neuronal and retinal cells by stem cell transplantation is therefore a promising approach to treat retinal ischemia.

The stem cells have an ability to self-renew and differentiate into specialized cells. They can act through various mechanisms. Stem cells can induce angiogenesis and thus, increase vascularization. Stem cells can also enhance the endogenous repair mechanisms, reduce inflammation, and release trophic factors. In the case of retinal ischemia, the eye is easily accessible for transplantation of stem cells. Thus, the stem cell therapy has a huge potential to restore visual function in case of retinal ischemia (Cogliati and Swaroop, 2009).

Stem cells from various sources have been used for treatment. Most commonly used are the stem cells from the bone-marrow as they are easier to obtain. Two types of cell population is present in the bone-marrow - hematopoietic progenitor cells and hematopoietic stem cells. The sub-population of hematopoietic stem cells has been shown to differentiate into lineage-negative and lineage-positive sub-types. This division is according to their ability to differentiate. The cells in lineage-negative fraction can lead to vascular endothelial cells or the endothelial precursor cells after the differentiation. These progenitor cells can then mobilize from the bone-marrow and home to target sites of angiogenesis in different injuries. Bone-marrow mesenchymal stem cells (BM-MSCs) differentiate into retinal neural cells in vivo and in vitro, and when implanted at a site of injury in experimental animal models, they show the ability to migrate to the injury site, initiate tissue repair, and restore function (Goes et al., 2008).

Another source of stem cells for the therapeutic purposes is those obtained from the early embryos. These embryonic stem cells have two characteristic properties, their ability to replicate indefinitely and their pluripotency. Thus the embryonic stem cells can differentiate into various cell types. These cells have also been tested in the cerebral ischemia model, showing structural as well as functional recovery (Wei et al., 2005). Various research groups have shown the potential of these stem cells in neurodegenerative diseases including retinal damage. The use of embryonic stem cells for transplantation has its own limitations. The foremost is the ethical concerns over its use and secondly there is a risk of immune rejection. To overcome these limitations, another stem cell source from non-pluripotent cells was discovered. In 2006, Takahashi and Yamanaka identified four transcription factors Oct3/4, Sox-2, Klf-4, c-myc. These factors can reprogram the DNA leading to the formation of stem cells from a non-pluripotent cell. These stem cells are known as induced pluripotent stem cells or iPCs (Takahashi and Yamanaka, 2006). iPCs have been used in various animal models and have shown to form different cell types. In humans, iPCs have been isolated from the patients with neurodegenerative disorders such as Parkinson's disease, muscular dystrophy, amyotrophic lateral sclerosis (Dimos et al., 2008; Park et al., 2008). iPCs have been used to generate human neuronal cells, photoreceptors, and retinal pigmented epithelium cells (Takahashi and Yamanaka, 2006; Hirami et al., 2009; Karumbayaram et al., 2009). Another source of stem cells that is being tested as a potential therapy is the umbilical cord blood. It has a large percentage of hematopoietic stem cells, higher than those found in bone-marrow and also these cells show lesser immune rejection.

Earlier the CNS was thought to be a non-renewable tissue in mammals. Neural stem cells are normally found in the developing CNS, but studies have shown that these are also present in adult CNS. These cells are found in restricted region of CNS, such as hippocampus, subventricular zone, spinal cord, and ependyma and

Table 1 | Advantages and limitations of different animal models of retinal ischemia.

\begin{tabular}{|c|c|c|}
\hline Animal model & Advantages & Limitations \\
\hline Elevation of intraocular pressure & $\begin{array}{l}\text { Temporary and reversible; easy to create and reproduce; } \\
\text { minimal requirement of surgery or special equipments }\end{array}$ & High IOP can cause damage \\
\hline Middle cerebral artery occlusion & Transient (can study reperfusion); reproducible & $\begin{array}{l}\text { Requires specialized skills; incomplete ischemia; alter } \\
\text { blood flow to the brain }\end{array}$ \\
\hline Chronic carotid occlusion & Reproducible; easy & Variable damage; permanent ischemia \\
\hline Photothrombosis of retinal vessels & Simple & $\begin{array}{l}\text { Variable degrees of exposure and variable damage; } \\
\text { permanent ischemia; free-radical damage }\end{array}$ \\
\hline Occlusion of central retinal artery & Complete retinal ischemia & - \\
\hline Endothelin administration & No inflammation or infection & Can enter systemic circulation \\
\hline
\end{tabular}


can form astrocytes, neurons, and oligodendrocytes. The neural stem cells were first isolated from adult rat hippocampus (Palmer et al., 1997). These cells have shown the ability to migrate and differentiate into neuronal cells in retinal injury (Nishida et al., 2000). But more studies need to be done to estimate the efficiency of the neural stem cells.

The stem cell transplantation in retina has some limitations, such as poor cell homing, cell migration, and integration. Thus, many of the transplanted cells do not reach the retina. A study has shown that only $1 \%$ of the cells transplanted intraocularly reach the retina (Johnson et al., 2010).

\section{REFERENCES}

Aiello, L. P., Pierce, E. A., Foley, E. D., Takagi, H., Chen, H., Riddle, L., Ferrara, N., King, G. L., and Smith, L. E. (1995). Suppression of retinal neovascularization in vivo by inhibition of vascular endothelial growth factor (VEGF) using soluble VEGF-receptor chimeric proteins. Proc. Natl. Acad. Sci. U.S.A. 92, 10457-10461.

Barnett, N. L., and Osborne, N. N. (1995). Suppression of retinal neovascularization in vivo by inhibition of vascular endothelial growth factor (VEGF) using soluble VEGFreceptor chimeric proteins. Exp. Eye Res. 61, 83-90.

Bennett, J., Wilson, J., Sun, D., Forbes, B., and Maguire, A. (1994). Adenovirus vector-mediated in vivo gene transfer into adult murine retina. Invest. Ophthalmol. Vis. Sci. 35, 2535-2542.

Block, F., Grommes, C., and Kosinski, C. (1997). Retinal ischemia induced by the intraluminal suture methods in rats. Neurosci. Lett. 232, 45-48.

Block, F., Schwarz, M., and Sontag, K. -H. (1992). Retinal ischemia induced by occlusion of both common carotid arteries in rats as demonstrated by electroretinography. Neurosci. Lett. 144, 124-126.

Buchi, E. R., Lam, T. T., Suvaizdis, I., and Tso, M. O. (1994). Injuries induced by diffuse photodynamic action in retina and choroid of albino rats. Morphologic study of an experimental model. Retina (Philadelphia, Pa.) 14, 370-378.

Buchi, E. R., Suivaizdis, I., and Fu, J. (1991). Pressure-induced retinal ischemia in rats: an experimental model for quantitative study. Ophthalmologica 203, 138-147.

Bursell, S. E., Clermont, A. C., Oren, B., and King, G. L. (1995). The in vivo effect of endothelins on retinal circulation in nondiabetic and diabetic rats. Invest. Ophthalmol. Vis. Sci. 36, 596-607.

Cao, W., Zaharia, M., Drumheller, A., Casanova, C., Lafond, G., Brunette, J.
R., and Jolicoeur, F. B. (1994). Effects of dextromethorphan on ischemia induced ERG changes in rabbit. Curr. Eye Res. 13, 97-102.

Cogliati, T., and Swaroop, A. (2009). Stems cells and neuronal repair. Ann. Neurosci. 16, 143-145.

Deveraux, Q. L., Takahashi, R., Salvesen, G. S., and Reed, J. C. (1997). X-linked IAP is a direct inhibitor of cell-death proteases. Nature 388, 300-304.

Di Polo, A., Aigner, L. J., Dunn, R. J., Prolonged delivery of brain-derived neurotrophic factor by adenovirusinfected Muller cells temporarily rescues injured retinal ganglion cells. Proc. Natl. Acad. Sci. U.S.A. 95, 3978-3983.

Dimos, J. T., Rodolfa, K. T., and Niakan, K. K. (2008). Induced pluripotent stem cells generated from patients with ALS can be differentiated into motor neurons. Science 321, 1218-1221.

Eberhardt, O., Coelln, R. V., Kugler, S., Lindenau, J., Rathke-Hartlieb, S., Gerhardt, E., Haid, S., Isenmann, S., Gravel, C., Srinivasan, A., Bähr, M., Weller, M., Dichgans, J., and Schulz, J. B. (2000). Protection by synergistic effects of adenovirusmediated X-chromosome-linked inhibitor of apoptosis and glial cell line-derived neurotrophic factor gene transfer in the 1-methyl-4phenyl-1,2,3,6-tetrahydropyridine model of Parkinson's disease. J. Neurosci. 20, 9126-9134.

Flannery, J. G., Zolotukhin, S., Vaquero, M. I., LaVail, M. M., Muzyczka, N., and Hauswirth, W. W. (1997). Efficient photoreceptor-targeted gene expression in vivo by recombinant adeno-associated virus. Proc. Natl. Acad. Sci. U.S.A. 94, 6916-6921.

Flower, R. W., and Patz, A. (1971). The effect of hyperbaric oxygenation on retinal ischemia. Invest. Ophthalmol. Vis. Sci. 10, 605-616.

Gilgun-Sherki, Y., Rosenbaum, Z., Melamed, E., and Offen, D. (2002). Antioxidant therapy in acute central Bray, G. M., and Aguayo, A. J. (1998).

\section{CONCLUSION}

Retinal ischemia is the clinical condition caused by insufficient supply of blood to retina and is found in many of the disorders. Retina, like the CNS originates from the ectoderm. Thus, with the use of animal models of retinal ischemia pathophysiology can be studied and therapeutic agents can be tested. Each of the animal models described in this review has its own advantages and limitations. Table 1 summarizes the advantages and limitations of the retinal ischemia models discussed in this review. Thus, the choice of animal models for pre-clinical testing will depend on the research problem involved.

nervous system injury: current state. Pharmacol. Rev. 54, 271-284.

Goes, A. M., Castanheira, P., Torquetti, L., and Nehemy, M. B. (2008). Retinal incorporation and differentiation of mesenchymal stem cells intravitreally injected in the injured retina of rats. Arq. Bras. Oftalmol. 71, 644-650.

Goldenberg-Cohen, N., Dadon, S. Avraham, B.-C. R., Kramer, M. Hasanreisoglu, M., Eldar, I., Weinberger, D., and Bahar, I. (2008). Molecular and histological changes following central retinal artery occlusion in a mouse model. Exp. Eye Res. 87, 327-333.

Hayreh, S. S. (1963). The central artery of the retina its role in the blood supply of the optic nerve. Br. J. Ophthalmol. 47, 651-663.

Hayreh, S. S., Kolder, H. E., and Weingeist, T. (1980). Central retinal artery occlusion and retinal tolerance time. Ophthalmology 87,75-78.

Henkind, P., Hansen, R. I., and Szalay, J. (1979). "Ocular circulation," in Physiology of the Human Eye and Visual System, ed. R. E. Records (New York: Harper and Row), 98-155.

Hirami, Y., Osakada, F., and Takahashi, K. (2009). Generation of retinal cells from mouse and human induced pluripotent stem cells. Neurosci. Lett. 458, 126-131.

Hirrlinger, P. G., Elke, U., Ianors, I., Andreas, R., and Thomas, P. (2010). Alterations in protein expression and membrane properties during Müller cell gliosis in a murine model of transient retinal ischemia. $\mathrm{Neu}$ rosci. Lett. 472, 73-78.

Holcik, M., Gibson, H., and Korneluk, R. G. (2001). XIAP: apoptotic brake and promising therapeutic target. Apoptosis 6, 253-261.

Ji, J., Chang, P., Pennesi, M. E., Yang, Z., Zhang, J., Li, D., Wu, S. M., and Gross, R. L. (2005). Effects of elevated intraocular pressure on mouse retinal ganglion cells. Vision Res. 45, 169-179.
Joachim, S. C., Wax, M. B., Boehm, N., Dirk, D., Pfeiffer, N., and Grus, F. H. (2011). Up-regulation of antibody response to heat shock proteins and tissue antigens in an ocular ischemia model. Invest. Ophthalmol. Vis. Sci. 52, 3468-3474.

Johnson, T. V., Bull, N. D., and Martin, K. R. (2010). Identification of barriers to retinal engraftment of transplanted stem cells. Invest. Ophthalmol. Vis. Sci. 51, 960-970.

Kaja, S., Yang, S. H., and Wei, J. (2003). Estrogen protects the inner retina from apoptosis and ischemiainduced loss of Vesl-1L/Homer-1c immunoreactive synaptic connections. Invest. Ophthalmol. Vis. Sci.44, 3155-3162.

Karumbayaram, S., Novitch, B. G., and Patterson, M. (2009). Directed differentiation of human-induced pluripotent stem cells generates active motor neurons. Stem Cells 27, 806-811.

Kliman, G. H., Puliafito, C. A., Grossman, G. A., and Gregory, W. A. (1994). Retinal and choroidal vessel closure using phthalocyanine photodynamic therapy. Lasers Surg. Med. 15, 11-18.

Kwon, Y. H., Rickman, D. W., Baruah, S., Zimmerman, M. B., Kim, C.S., Boldt, H. C., Russell, S. R., and Hayreh, S. S. (2005). Vitreous and retinal amino acid concentrations in experimental central retinal artery occlusion in the primate. Eye 19, 455-463.

Lam, T. T., Siew, E., Chu, R., and Tso, M. O. (1997). Ameliorative effect of MK-801 on retinal ischemia. J. Ocul. Pharmacol. Ther. 13, 129-137.

Lavinsky, D., Arterni, N. S., Achaval, M., and Netto, C. A. (2006). Chronic bilateral common carotid artery occlusion: a model for ocular ischemic syndrome in the rat. Graefes Arch. Clin. Exp. Ophthalmol. 244, 199-204. 
Lenka, N., and Anand, A. (2009). Advancements in stem cell research: an Indian perspective - I. Ann. Neurosci. 16, 97.

Masuzawa, K., Jesmin, S., Maeda, S., Kaji, Y., Oshika, T., Zaedi, S., and Shimojo, N. (2006). A model of retinal ischemia-reperfusion injury in rats by subconjuctival injection of endothelin-1. Exp. Biol. Med. 231, 1085-1089.

McKinnon, S. J., Lehman, D. M., Tahzib, N. G., Ransom, N. L., Reitsamer, H. A., Liston, P., LaCasse, E., Li, Q., Korneluk, R. G., and Hauswirth, W. W. (2002). Baculoviral IAP repeatcontaining-4 protects optic nerve axons in a rat glaucoma model. $\mathrm{Mol}$. Ther. 5, 780-787.

Melena, J., Wood, J. P. M., and Osborne, N. N. (1999). Betaxolol, a B1adrenoceptor antagonist, has an affinity for L-type $\mathrm{Ca}^{2+}$ channels. Eur. J. Pharmacol. 378, 317-322.

Miller, J. W., Adamis, A. P., Shima, D. T., D'Amore, P. A., Moulton, R. S., O'Reilly, M. S., Folkman, J., Dvorak, H. F., Brown, L. F., and Berse, B. (1994). Vascular endothelial growth factor/vascular permeability factor is temporally and spatially correlated with ocular angiogenesis in a primate model. Am. J. Pathol. 145, 574-584.

Mosinger, J. L., and Olney, J. W. (1989). Photothrombosis-induced ischemic neuronal degeneration in the rat retina. Exp. Neurol. 105, 110-113.

Nishida, A., Zakahashi, M., Tauihara, H., Nakamo, I., Tahahashi, J. B., Mizoguchi, A., Ide, C., and Honda, Y. (2000). Incorporation and differentiation of hippocampus-derived neural stem cells transplanted in injured adult rat retina. Invest. Ophthalmol. Vis. Sci. 41, 4268-4269.

Ogata, N., Wang, L., Jo, N., TombranTink, J., Takahashi, K., Mrazek, D., and Matsumura, M. (2001). Pigment epithelium derived factor as a neuroprotective agent against ischemic retinal injury. Curr. Eye Res. 22, 245-252.

Osborne, N. N., DeSantis, L., Bae, J. H., Ugarte, M., Wood, J. P. M., Nash, M. S., and Chidlow, G. (1999). Topically applied betaxolol attenuates NMDAinduced toxicity to ganglion cells and the effects of ischemia to the retina. Exp. Eye Res. 69, 331-342.

Palmer, T. D., Takahashi, J., and Gage, F. H. (1997). The adult rat hippocampus contains primordial neural stem cells. Mol. Cell. Neurosci. 8, 389-404.
Park, I. H., Arora, N., Huo, H., Maherali, N., Ahfeldt, T., Shimamura, A., Lensch, M. W., Chad, C., Hochedlinger, K., and Daley, G. Q. (2008). Disease-specific induced pluripotent stem cells. Cell 134, 877-886.

Peachey, N. S., Green, D. J., and Ripps, H. (1993). Ocular ischemia and the effects of allopurinol on functional recovery in the retina of the arterially perfused cat eye. Invest. Ophthalmol. Vis. Sci. 34, 58-65.

Petrin, D., Baker, A., Coupland, S. G., Liston, P., Narang, M., Damji, K., Leonard, B., Chiodo, V. A., Timmers, A., Hauswirth, W., Korneluk, R. G., and Tsilfidis, C. (2003). Structural and functional protection of photoreceptors from MNUinduced retinal degeneration by the X-linked inhibitor of apoptosis. Invest. Ophthalmol. Vis. Sci. 44, 2757-2763.

Prasad, S. S., Kojic, L., Wen, Y. H., Chen, Z., Xiong, W., Jia, W., and Cyander, M. S. (2010). Retinal gene expression after central retinal artery ligation: effects of ischemia and reperfusion. Invest. Ophthalmol. Vis. Sci. 51, 6207-6219.

Renwick, J., Narang, M. A., Coupland, S. G., Xuan, J. Y., Baker, A. N., Brousseau, J., Petrin, D., Munger, R., Leonard, B. C., Hauswirth, W. W., Korneluk, R. G., and Tsilfidis, C. (2006). XIAP-mediated neuroprotection in retinal ischemia. Gene Ther. 13, 339-347.

Rios, L., Cluzel, J., Vennat, J. C., Menerath, J. M., and Doly, M. J. (1999). Comparison of intraocular treatment of DMTU and SOD following retinal ischemia in rats. J. Ocul. Pharmacol. Ther. 15, 547-556.

Rumelt, S., Dorenboim, Y., and Rehany, U. (1999). Aggressive systematic treatment for central retinal artery occlusion. Am. J. Ophthalmol. 128, 733-738.

Saint-Geniez, M., and D'Amore, P. A. (2004). Development and pathology of the hyaloid, choroidal and retinal vasculature. Int. J. Dev. Biol. 48, 1045-1058.

Sakaue, H., Kiryu, J., Takeuchi, A., Yamamoto, F., and Honda, Y. (1992). Effects of endothelin on retinal blood vessels. Nippon Ganka Gakkai Zasshi 96, 469-472.

Sato, T., Takei, K., Nonoyama, T., Miyauchi, T., Goto, K., and Hommura, S. (1993). Endothelin-1induced vasoconstriction in retinal blood vessels in the rabbit. Nippon Ganka Gakkai Zasshi 97, 683-689.

Schmidt-Kastner, R., and Eysel, U. T. (1994). Ischemic damage visualized in flat mounts of rat retina after photochemically induced thrombosis. Brain Res. Bull. 34, 487-491.

Shibuki, H., Katai, N., Kuroiwa, S., Kurokawa, T., Arai, J., Matsumoto, K., Nakamura, T., and Yoshimura, N. (2002). Expression and neuroprotective effect of hepatocyte growth factor in retinal ischemiareperfusion injury. Invest. Ophthal mol. Vis. Sci. 43, 528-536.

Smith, G. G., and Baird, C. D. (1952). Survival time of retinal cells when deprived of their blood supply by increased intraocular pressure. Am. J. Ophthalmol. 35, 133-136.

Steele, E. C., Guo, Q., and Namura, S. (2008). Filamentous middle cerebral artery occlusion causes ischemic damage to retina in mice. Stroke 39, 2099-2104.

Takahashi, K., and Yamanaka, S. (2006). Induction of pluripotent stem cells from mouse embryonic and adult fibroblast cultures by defined factors. Cell 126 663-676.

Takei, K., Sato, T., Nonoyama, T. Miyauchi, T., Goto, K., and Hommura, S. (1993). A new model of transient complete obstruction of retinal vessels induced by endothelin-1 injection into the posterior vitreous body in rabbits. Graefes Arch. Clin. Exp. Ophthalmol. 231 , 476-481.

Tso, M. O., and Jampol, L. M (1982). Pathophysiology of hypertensive retinopathy. Ophthalmology 89, 1132-1145.

Unoki, K., and LaVail, M. M. (1994). Protection of the rat retina from ischemic injury by brainderived neurotrophic factor, ciliary neurotrophic factor, and basic fibroblast growth factor. Invest. Ophthalmol. Vis. Sci. 35, 907-915.

von Graefe, A. (1859). Ueber Embolie der Arteria centralis retinae als Ursache plotzlicher Erblindung. Albrecht Von Graefes Arch. Ophthalmol. 5, 136-157.

Wei, L., Cui, L., Snider, B. J., Rivkin, M., Yu, S. S., Lee, C. S., Adams, L. D., Johnso, E. M., Yu, S. P., and Choi, D. W. (2005). Transplantation of embryonic stem cells overexpressing Bcl-2 promotes functional recovery after transient cerebral ischemia. Neurobiol. Dis. 19, 183-193.

Wu, W.-C., Lai, C.-C., Chen, S.-L., Sun, M.-H., Xiao, X., Chen, T.L., Tsai, R. J.-F., Kuo, S.-W., and Tsao, Y.-P. (2004). GDNF gene therapy attenuates retinal ischemic injuries in rats. Mol. Vis. 10, 93-102.

Xu, D., Bureau, Y., McIntyre, D. C., Nicholson, D. W., Liston, P., Zhu, Y., Fong, W. G., Crocker, S. J., Korneluk, R. G., and Robertson, G. S. (1999). Attenuation of ischemia-induced cellular and behavioural deficits by $\mathrm{X}$ chromosome-linked inhibitor of apoptosis protein overexpression in the rat hippocampus. J. Neurosci. 19, 5026-5033.

Yanagisawa, M., Kurihara, H., Kimura, S., Tomobe, Y., Kobayashi, M., Mitsui, Y., Yazaki, Y., Goto, K., and Masaki, T. (1988). A novel potent vasoconstrictor peptide produced by vascular endothelial cells. Nature 332, 411-415.

Zhang, Y., Cho, C.-H., Atchaneeyasakul, L.-O., McFarland, T., Appukuttan, B., and Stout, J. T. (2005). Activation of the mitochondrial apoptotic pathway in a rat model of central retinal artery occlusion. Invest. Ophthalmol. Vis. Sci. 46, 2133-2139.

Conflict of Interest Statement: The authors declare that the research was conducted in the absence of any commercial or financial relationships that could be construed as a potential conflict of interest.

Received: 12 January 2012; accepted: 16 April 2012; published online: 11 May 2012.

Citation: Minhas G, Morishita $R$ and Anand A (2012) Preclinical models to investigate retinal ischemia: advances and drawbacks. Front. Neur. 3:75. doi: 10.3389/fneur.2012.00075

This article was submitted to Frontiers in Neuro-Ophthalmology, a specialty of Frontiers in Neurology.

Copyright (C) 2012 Minhas, Morishita and Anand. This is an open-access article distributed under the terms of the Creative Commons Attribution Non Commercial License, which permits noncommercial use, distribution, and reproduction in other forums, provided the original authors and source are credited. 